\title{
Short-term memory: Where do we stand?
}

\author{
ROBERT G. CROWDER \\ Yale University, New Haven, Connecticut
}

\begin{abstract}
Two empirical challenges to the traditional "modal model" of short-term memory are that neither the Brown-Peterson distractor technique nor the recency effect in recall is well accommodated by that position. Additionally, the status of memory stores as such, has declined in response to proceduralist thinking. At the same time, the concept of coding, on which the modal model is silent, is increasingly central to memory theory. People need to remember things in the short term, but a dedicated store does not need to be the agency.
\end{abstract}

The duration of the debate about short-term memory corresponds almost exactly to the time I have so far spent as a psychologist. Progress has been made, but we are still searching for a way to understand the concept of short-term memory; in this paper, I intend to provide the context for that search.

Early suggestions that experimental tasks such as the Brown-Peterson distractor task could provide a direct look at short-term memory were soon replaced by the so-called modal model, originally articulated by Waugh and Norman (1965) and soon refined by Atkinson and Shiffrin (1968). I propose four challenges to that model. The first two challenges are empirical, and the last two are theoretical.

1. The distractor task. The concept of short-term storage provided a handy explanation for the rapid loss of information over a few seconds of distraction (Peterson $\&$ Peterson, 1959). This suggestion was called into question by the data of Keppel and Underwood (1962), which showed that distraction does not cause any appreciable loss of information on the very first trial of an experiment. The modal model must explain this first-trial performance as somehow reflecting long-term memory (Cowan, 1988, p. 169; Waugh \& Norman, 1965). Of course, the verbal item was demonstrably very familiar to subjects before they ever walked into the experimental room; therefore, it was "in" long-term memory, so the modal model must maintain that it was the occurrence of that item in that time and place that is somehow registered in long-term memory. But, such an active state of information in long-term memory is what some workers mean by short-term memory to start with.

So, we cannot take performance in the distractor task as an uncontaminated signature of short-term memory. But models are more usually overthrown by better, alternative models than by data. And as it happens, an alternative hypothesis based on temporal distinctiveness (Crowder \& Neath, 1991; Glenberg \& Swanson, 1986; Johnson, 1991) readily explains the empirical facts from

Correspondence should be addressed to R. G. Crowder, Department of Psychology, Yale University, Box 11A, Yale Station, New Haven, CT 06520-7447. distractor experiments, including certain temporal features of the task that are quite foreign to the modal model.

As an example of the latter, Turvey, Brick, and Osborn (1970) showed that performance sometimes does not decline regularly with the duration of distractor activity in the Brown-Peterson paradigm. Such flat forgetting functions occur when the retention interval is varied between subjects, rather than within subjects, as is usually done. We have recently replicated this finding in an informal classroom project. A point of view based on distinctiveness in memory, analogous to distinctiveness in perception (Crowder \& Neath, 1991; Glenberg \& Swanson, 1986; Johnson, 1991; Murdock, 1960), can explain this result, whereas it is simply incomprehensible according to the modal model. Murdock suggested that serialposition phenomena might be understood by reference to a spatial array in vision, where the end items are perceptually more distinctive than the intermediate items. Modern versions of the temporal-distinctiveness idea derive in one way or another from this insight.

2. Recency. The recency effect in free recall was a second obvious consequence of forgetting in short-term memory, and for years it was considered the signature of that process. This assignment of recency to short-term memory is still sanctified in textbooks, but it was challenged by the discovery of long-term recency (Bjork \& Whitten, 1974; Tzeng, 1973).

Recently, Koppenaal and Glanzer (1990) have claimed that we dismissed the modal model prematurely. They showed that changing the distractor task after the last item on a list depresses performance on the last item. Their interpretation of long-term recency was that, in the distractor paradigm, people grow accustomed to the distractor task and can carry out rehearsal of the recency items at the same time. In other words, people might learn to maintain a recency buffer despite the distractor task. This should grow with practice, but should be disrupted by changing the distractor task associated with the last item, which is what they found. So, Koppenaal and Glanzer said that recency comes from the sort of temporary rehearsal buffer stipulated by the modal model, even in the longterm-recency paradigm. 
However, Neath (1991) has refuted this defense of the revised interpretation of recency. He showed that a changed distractor task damages performance wherever in a list it may occur-after the first item, after the third, or at the end. Since performance at these earlier positions was not presumed to have been supported by a rehearsal buffer, it follows that some other factor is at work.

Other instances of recency in long-term memory are equally awkward for the modal model. Baddeley and Hitch (1977) showed that patrons of local pubs recalled the teams playing against the local rugby team that season with a strong recency bias. Roediger and Crowder (1976) showed a serial-position effect in recall of the names of U.S. presidents, with primacy and recency defined by their historical terms. Figure 1 shows a recent update of those data, based on responses from undergraduate students at Rice and Yale universities. Public figures such as Nixon and Ford, the beneficiaries of powerful recency effects 15 years ago, have now given way to newer incumbents.

My point in mentioning the rugby and presidential recalls is that a rehearsal buffer is preposterous as an explanation for why the last few items in the series are so well remembered. Of course, it may be a coincidence that the empirical recency effects match in the experimental and the historical situations. On the other hand, one respectable theory of recency, described above as the distinctiveness hypothesis, handles both situations with ease. It seems to me the burden of evidence should be with those who say these two, similar recency effects are caused by different mechanisms. Recency in what used to be called long-term memory has recently been examined by Greene (1986) and Nairne (1991), who both concluded that longand short-term recency obey similar rules.

Notice that the distinctiveness hypothesis stands as a viable alternative for both the Brown-Peterson distractor task and the recency effect. It may turn out that these two phenomena are intimately related to one another after all-not through their common dependence on short-term memory, but through their common dependence on distinctiveness.

3. Memory stores in general. If dedicated memory stores do not exist, as such, then there can be no shortterm store. The popularity of short-term stores grew during a time when we were busy inventing such storage receptacles. Nowadays that attitude seems archaic and, to some of us, even downright quaint.

Increasingly, the field is turning instead to a procedural attitude toward memory. This was evident in the levelsof-processing hypothesis of Craik and Lockhart (1972), and it was most explicit in the research of Paul Kolers (Kolers \& Roediger, 1984). According to proceduralism, memory storage occurs in the same neural units that processed the information at the time of original acquisition. This is exactly what Hebb (1949) said long ago, in advancing his dual-trace mechanism. Hebb believed that one mechanism for the storage of memories was the continued activity, or reverberation, of the cells and cell assemblies recruited by a perceptual act. I will return to this reverberatory activity as the true origin of the short-termmemory hypothesis. The second mechanism for memory was Hebb's proposal that if reverberatory activity con-

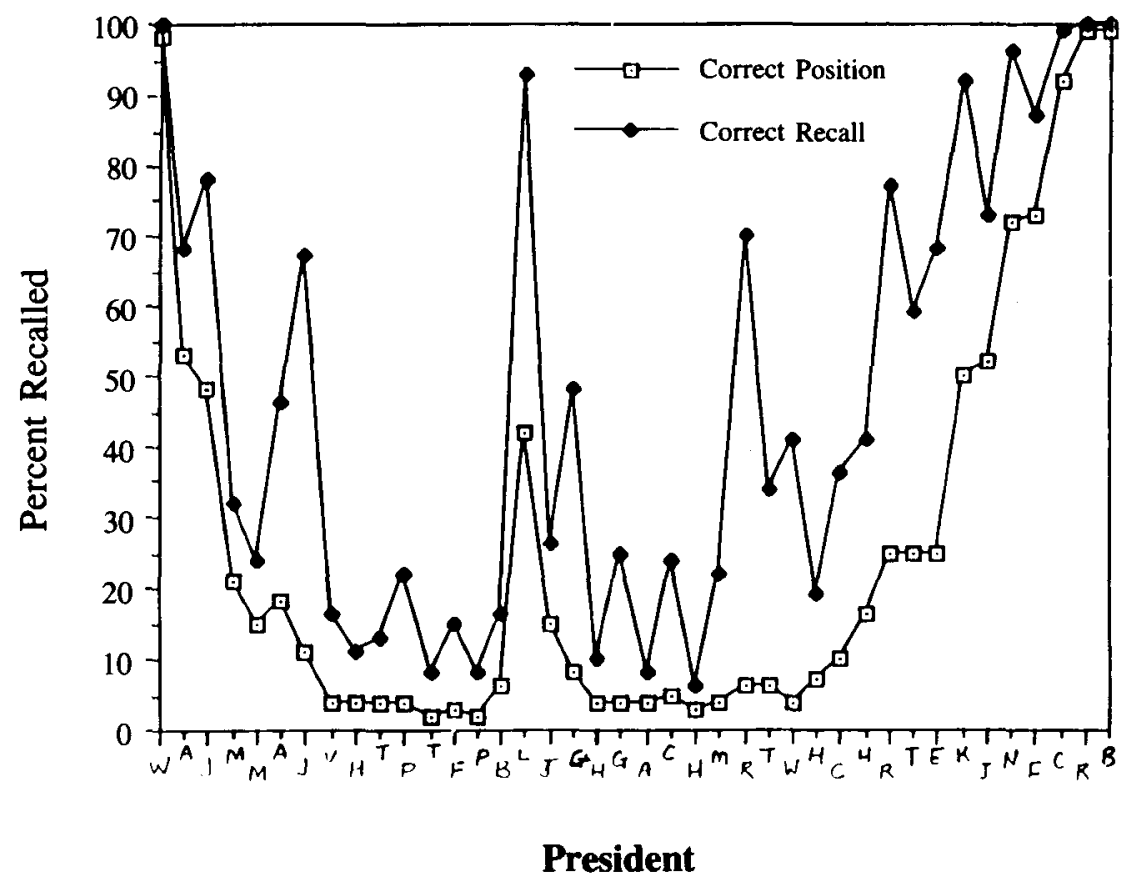

Figure 1. Recall of the names of U.S. presidents. Data from Yale University $(n=46)$ and Rice University $(n=60)$ undergraduates, the latter courtesy of H. L. Roediger III. 
tinued long enough, there would be structural changes in those same neural units, which would carry memory indefinitely. Thus, Hebb can now be seen as the first proceduralist as well as the first modern connectionist.

Proceduralism is a rejection of the spatial metaphor in memory (Roediger, 1980), and I should not insist that acceptance of short-term memory, in all its forms, commits one to that spatial metaphor. I have just suggested that Hebb was a procedural theorist, and yet his dual-trace mechanism for memory originated one view of short-term storage. Schneider and Detweiler (1987) have related new proposals for fast and slow weight changes within a connectionist architecture. This amounts to a distinction between long- and short-term processing.

4. Coding. Almost from the start, the concept of shortterm memory was confounded with coding. Baddeley (1966) was among several workers who identified the short-term store with coding by speech and the long-term store with semantic coding. The distinction between longand short-term memory is, of course, completely neutral about coding. But, once different codes are assigned to the two memory mechanisms, we have a fundamental confounding: Which is the more important, the distinction in storage times or the distinction in codes?

We all know what we are supposed to do in order to disentangle confounded factors: hold one factor constant while varying the other. This would mean remaining within parameters of short- or long-term storage while varying coding, say, between phonetic and semantic dimensions. Alternatively, one could remain within one coding format and vary whether short- or long-term memory is being measured. This is easier said than done. Shulman (1970) had such a strategy in mind when he looked for a diversity of coding formats within the recency effect in a short-term-memory task, but few investigators have followed his lead. Another demonstration would be to show that visual images have different properties when used with the classic mnemonic techniques than when used in a short-term-memory or working-memory situation.

The same confounding problem-between coding and putative stores-is particularly acute in interpreting deficits in neuropsychology patients (Vallar \& Shallice, 1990). Are such patients, with selective impairments in certain tasks, missing an early stage in neural processing across the entire system, or are they missing, instead, the neural machinery involved in a particular form of coding, say, phonological? These and related issues have been discussed by Martin (1993).

Crowder and Neath (1991) suggested, on the basis of considerations raised here, that the proper metaphor for short-term memory was with the microscope: Ordinary things look strange when placed under a high-powered microscope, but they are not, in fact, different objects. They just look different because the detailed structure of an object is apparent under a microscope in a way it is not to the naked eye. In memory, the dimension being exploded by the microscopic view is time, rather than space, but the same logic applies. Indeed, Peterson and
Peterson (1959) explicitly thought they were studying what happens to a single item during the time span of a single trial in a list-learning experiment.

\section{Does Short-Term Memory Exist?}

The answer to this question must surely be "yes," and in two senses:

Memory in the short term. First of all, people must be able to retain information over brief intervals of time. This is beyond argument as a general proposition, even though the necessity of verbatim memory in psycholinguistics has recently come under interesting criticism by Potter and Lombardi (1990). But, needing to retain information over brief intervals really means that human beings require memory, not that it need be a dedicated subsystem with different properties from other subsystems. I remarked recently (Crowder \& Neath, 1991) that we need working memory in the sense of memory that works, not in the conventional sense of that term. We should be vigilant in distinguishing between (1) cases requiring memory over short intervals of time and (2) cases requiring a dedicated subsystem of short-term storage.

Hebb's dual-trace theory. Even the most devoted proceduralist is hard pressed to maintain that all memories are based on continued activity in the neural units that encoded the original experience. This would be hard to imagine for intact memories that might date back years, or even decades (Squire, Slater, \& Chace, 1975). Hebb (1949) proposed that if the original activity continues for some period, a second agency, structural changes at the synaptic contacts among cells, could carry the memory thereafter. These structural changes would correspond to long-term memory, many thought, and the earlier continued activity-reverberation-might be identified with short-term memory.

Now, we can hardly imagine a system where structural change takes place instantaneously upon simultaneous activity of an assembly of cells. As Miller and Marlin (1984) have pointed out, if we accept that some period of activity is necessary for structural changes, we must, therefore, believe in some version of a consolidation theory. This is the second sense in which short-term memory must exist.

The question is whether the "activity trace" as described originally by Hebb (1949) — nowadays called short-term storage-is useful in describing any observed behavior. Miller and Marlin (1984) concluded that it is not useful for the disorder of amnesia. Hebb (1961) reported an experiment he had anticipated over a decade earlier (Hebb, 1949) and admitted that his own prediction had been wrong: What he had taken to be a perfect case of an activity trace without structural tracesimmediate memory span-turned out to lead to durable learning (Hebb, 1949). For different reasons, Watkins and his colleagues (Brooks \& Watkins, 1990; Watkins, 1977) also rejected the notion that memory span marks the limit on a unitary process. At best, modern workers must hold out for some contribution of an agency like the activity 
trace, among other contributors, to the observed memory span (as with the distractor task).

Earlier in this paper, I discussed two other situations that were once thought to be defining marks of short-term memory-the Brown-Peterson distractor task and the recency effect in free recall. Neither of them, as it happens, requires a process of short-term memory. Indeed, such a process is incapable of explaining either one in detail. Therefore, although some sort of transient activity trace-or short-term storage-must exist, it seems to play no obvious role in explaining behavior.

\section{The Conscious Present}

We are left with the intuitions so brilliantly articulated in the famous passage about primary memory by William James (1890/1983). I share these intuitions with James, but I do not trust them for a moment: What seems to be part of the conscious present and what seems to have passed into an earlier time must have more to do with the perception of time itself than it does with forms of memory, the more so as we learn that many manifestations of learning and memory never enter into consciousness at all, either as part of the present or as part of the past.

Our intuitive observations about how our memories work must resemble people's intuitive observations, in earlier times, of how astronomy worked. Those intuitions are the same ones that led to a firm belief in a geocentric universe and a flat earth.

\section{REFERENCES}

Atkinson, R. C., Shiffrin, R. M. (1968). Human memory: A proposed system and its control processes. In K. W. Spence \& J. T. Spence (Eds.), The psychology of learning and memory (Vol. 2, pp. 89-195). New York: Academic Press.

BADDELEY, A. D. (1966). The influence of acoustic and semantic similarity on long-term memory for word sequences. Quarterly Journal of Experimental Psychology, 18, 302-309.

Baddeley, A. D., \& Hitch, G. J. (1977). Recency reexamined. In S. Dornic (Ed.), Attention and performance (Vol. 6, pp. 647-667). Hillsdale, NJ: Erlbaum.

BJoRK, R. A., WhITTEN, W. B. (1974). Recency-sensitive retrieval processes in long-term free recall. Cognitive Psychology, 6, 173-189.

Brooks, J. O., III., \& WATKINS, M. J. (1990). Further evidence of the intricacy of memory span. Journal of Experimental Psychology: Learning, Memory, \& Cognition, 16, 1134-1141.

Cowan, N. (1988). Evolving conceptions of memory storage, selective attention, and their mutual constraints within the human information-processing system. Psychological Bulletin, 104, 163-191.

Craik, F. I. M., LockHART, R. S. (1972). Levels of processing: A framework for memory research. Journal of Verbal Learning \& Verbal Behavior, 11, 671-684.

Crowder, R. G., Neath, I. (1991). The microscope metaphor in human memory. In W. E. Hockley \& S. Lewandowsky (Eds.), Relating theory and data: Essays on human memory in honour of Bennet B. Murdock, Jr. (pp. 111-125). Hillsdale, NJ: Erlbaum.

Glenberg, A. M., Swanson, N. C. (1986). A temporal distinctiveness theory of recency and modality effects. Journal of Experimental Psychology: Learning, Memory, \& Cognition, 12, 3-24.

Greene, R. L. (1986). A common basis for recency effects in immediate and delayed recall. Journal of Experimental Psychology: Learning. Memory, \& Cognition, 12, 413-418.
HeBB, D. O. (1949). Organization of behavior. New York: Wiley. Hes8, D. O. (1961). Distinctive features of learning in the higher anjmal. In J. F. Delafresnaye (Ed.), Brain mechanisms and learning. New York: Oxford University Press.

JAMES, W. (1983). The principles of psychology. Cambridge: Harvard University Press. (Original work published 1890)

Johnson, G. J. (1991). A distinctiveness model of serial learning. Psychological Review, 98, 204-217.

KePPEl, G. \& Underwood, B. J. (1962). Proactive inhibition in shortterm retention of single items. Journal of Verbal Learning \& Verbal Behavior, 1, 153-161.

Kolers, P. A., \& Roediger, H. L., III. (1984). Procedures of mind. Joumal of Verbal Learning \& Verbal Behavior, 23, 425-449.

Koppenaal, L., Glanzer, M. (1990). An examination of the continuous distractor task and the "long-term recency effect." Memory \& Cognition, 18, 183-195.

MARTIN, R. C. (1993). Short-term memory and sentence processing: Evidence from neuropsychology. Memory \& Cognition, 21, 176-183.

Miller, R. R., Marlin, N. A. (1984). The physiology and semantics of consolidation. In H. Weingartner \& E. S. Parkers (Eds.), Memory consolidation: Psychobiology of cognition (pp. 85-110). Hillsdale. NJ: Erlbaum.

Murdock, B. B., Jr. (1960). The distinctiveness of stimuli. Psychological Review, 67, 16-31.

NAIRNE, J. S. (1991). Positional uncertainty in long-term mernory. Memory \& Cognition, 19, 332-340.

NEATH, I. (1991). Context and distinctiveness in memory: Evidence for a two-stage process of retrieval. Unpublished doctoral dissertation, Yale University, New Haven, Connecticut.

Peterson, L. R., \& Peterson, M. J. (1959). Short-term retention of individual items. Journal of Experimental Psychology, 61, 12-21.

PotTer, M. C., Lombardi, L. (1990). Regeneration in the shortterm recall of sentences. Joumal of Memory \& Language, 29, 633-654.

ROEDIGER, H. L., III. (1980). Memory metaphors in cognitive psychology. Memory \& Cognition, 8, 231-246.

Roediger, H. L., III, Crowder, R. G. (1976). A serial position effect in recall of United States presidents. Bulletin of the Psychonomic Society, 8, 275-278.

SCHNEIDER, W. (1993). Varieties of working memory as seen in biology and in connectionist/control architectures. Memory \& Cognirion, 21, 184-192.

SChNeider, W., DetWeiler, M. (1987). A connectionist/control architecture for working memory. In G. H. Bower (Ed.). The psychology of leaming and memory (Vol. 2). New York: Academic Press.

SHULMAN, H. G. (1970). Encoding and retention of semantic and phonetic information in short-term memory. Journal of Verbal Learning \& Verbal Behavior, 9, 499-508.

Squire, L. R., Slater, P. C., Chace, P. M. (1975). Retrograde amnesia: Temporal gradient in very long-term memory following electroconvulsive therapy. Science, 187, 77-79.

Turvey, M. T., Brick, P., Osborn, J. (1970). Proactive interference in short-term memory as a function of prior-item retention interval. Quarterly Joumal of Experimental Psychology, 22, 142-147.

Tzeng, O. J. L. (1973). Positive recency effect in delayed free recall. Joumal of Verbal Learning \& Verbal Behavior, 12, 436-439.

VAllar, G., \& Shallice, T. (Eds.). (1990). Neuropsychological impairments of short-term memory. Cambridge: Cambridge University Press.

WatkINS, M. J. (1977). The intricacy of memory span. Memory \& Cognition, 5, 529-534.

Waugh, N. C., Norman, D. A. (1965). Primary memory. Psychological Review, 72, 89-104.

(Manuscript received April 1, 1992; revision accepted for publication June 24, 1992.) 